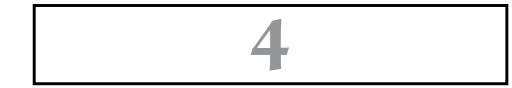

\title{
ASPECTOS CONTROVERTIDOS DAS RELAÇÕES ENTRE AS NORMAS DE PLANEJAMENTO ORÇAMENTÁRIO
}

O planejamento governamental, como já se pôde constatar ao longo do trabalho que vem sendo desenvolvido, abrange um sistema composto de normas que devem ser coordenadas de modo a estabelecer, de forma coesa e que permita dar segurança jurídica a toda a sociedade, os rumos de longo, médio e curto prazos do setor público. Sendo o Direito instrumento de segurança, que tem na previsibilidade da ação estatal uma expressão da segurança jurídica, ${ }^{1}$ as normas de planejamento, voltadas a direcionar a ação do setor público, passam a assumir uma dimensão de importância central no ordenamento jurídico.

Vários são os meios pelos quais se materializam esses instrumentos de planejamento governamental, definindo estratégias, diretrizes, objetivos e metas para períodos que podem variar de décadas a prazos inferiores a um ano. Mensagens de chefes do Poder Executivo, estudos de órgãos governamentais oficiais, normas que

Nesse sentido, sempre vale lembrar as palavras do Professor Geraldo Ataliba: "O Direito é, por excelência, acima de tudo, instrumento de segurança. Ele é que assegura a governantes e governados os recíprocos direitos e deveres, tornando viável a vida social. Quanto mais segura uma sociedade, tanto mais civilizada" (...) "Assim, a segurança jurídica expressa-se praticamente na previsibilidade da ação estatal" (...) "Assim se vê que certeza, confiança, lealdade, autorização, consentimento, segurança, previsibilidade, representatividade - república, enfim -, dão consistência e dimensão densas ao chamado princípio da certeza do direito. De fato, lei prévia é a conhecida pelo cidadão antes que tome suas decisões, antes que determine seu comportamento em assuntos que possam sofrer direta ou indiretamente influência da ação dos poderes públicos. É na linha destas diretrizes, respeitando esta tônica, caminhando no rumo assim estabelecido, que se dará interpretação às normas de direito público, acomodando a ação do Estado às exigências capitulares do princípio republicano" (ATALIBA, Geraldo. República e Constituição, p. 180-183). 
podem ser próprias do Poder Executivo, como os decretos, no caso brasileiro, e as leis propriamente ditas, atos emanados do Poder Legislativo competente, veiculam o planejamento governamental.

São muitas as possibilidades e variações encontradas nos diversos países do mundo na forma encontrada para exteriorização e materialização do planejamento governamental. Nelas, no mais das vezes, não se pode dissociar o planejamento ora referido como planejamento econômico governamental do planejamento orçamentário da administração pública, este último objeto de nosso estudo, dada a intensa inter-relação entre os institutos, como já tratado no início deste trabalho. Mais voltados ao planejamento orçamentário governamental estão os sistemas criados para cuidar do planejamento das despesas, especialmente os grandes investimentos, cuja relevância é maior para a definição dos rumos da Administração Pública no aspecto financeiro, impactando diretamente na formulação dos orçamentos e na definição das despesas de forma mais específica. Premchand faz referência ao fiscal planning, já mencionado anteriormente (item 1.3), que tem âmbito mais restrito, direcionado ao planejamento dos futuros orçamentos, com a definição das alocações de recursos para as dotações destinadas a atingir os objetivos e as metas estabelecidos (em contraposição ao development planning, de concepção mais abrangente, voltado ao papel do setor público no desenvolvimento econômico nacional) $;^{2}$ e, ainda, ao expenditure planning, um verdadeiro planejamento orçamentário plurianual, contendo previsōes de gastos futuros elaboradas no contexto do processo orçamentário, no bojo do que consta dos planos de desenvolvimento, para direcionar os recursos na elaboração do orçamento. ${ }^{3}$ Também o Medium-Term Expenditure Framework (MTEF), ${ }^{4}$ cuja referência encontra-se em muitos trabalhos produzidos principalmente pela OCDE, em que se verifica a diversidade de instrumentos adotados pelos países que formalizam previsōes de médio prazo balizadoras dos orçamentos anuais, estabelecendo sistemas de planejamento orçamentário. ${ }^{5}$ Nazaré Cabral enumera exemplos de sistemas e instrumentos adotados

PREMCHAND, A. Government budgeting and expenditure controls. Theory and practice, p. 176. PREMCHAND, A. Government budgeting and expenditure controls. Theory and practice, p. 205. Ao qual também já fizemos menção no item 1.3.

Nesse sentido, cabe destaque à observação de Nazaré Cabral: “Os países têm vindo a consagrar 'esquemas' diferenciados de programação financeira que se traduzem, grosso modo, na aprovação, em sentido restrito e formal, de quadros financeiros de médio prazo que formatem a tomada das decisões orçamentais. De notar, por outro lado, a tendência para uma imbricação ou plasmação da programação financeira em sentido lato com a orçamentação, o que conduz, à concretização de formas diversas de 'programação orçamental' ('medium-term budget framework' ou 'multi-year budgeting')" (Programação e decisão orçamental. Da racionalidade das decisões orçamentais à racionalidade económica, p. 207-210). 
por diversos países ao longo do tempo, em que se pode notar essa grande diversidade existente. $^{6}$

Nessa ampla gama de possibilidades de instrumentos que materializam o planejamento governamental, e especialmente no aspecto que interessa ao desenvolvimento deste trabalho, que é o planejamento vinculado à orçamentação, é necessário analisar questóes fundamentais para que se reconheça presente um sistema organizado, coeso e juridicamente seguro de planejamento orçamentário governamental. E a segurança jurídica do planejamento guarda estreito vínculo com o orçamento, como bem destaca Cabral de Moncada: "um dos processos de reforçar a eficácia jurídica do plano é o de o relacionar com o orçamento"?

É imprescindível que um sistema dessa natureza seja bem coordenado, especialmente quando se trata de países como o Brasil, de grandes dimensóes, em todos os sentidos - territorial, populacional etc. -, cujo Estado é organizado na forma federativa, com clara separação de poderes, em regime presidencialista.

A segurança jurídica desse sistema faz-se também absolutamente necessária, pois um sistema cuja eficácia está intrinsecamente ligada à concretização de atos voltados a previsões futuras, dela depende para seu sucesso, que ficará severamente comprometido se for ausente ou precária.

Isso requer instrumentos dotados de respaldo democrático, legitimidade, clareza, precisão e força capazes de assegurar à sociedade que o sistema tenha confiabilidade.

O Brasil, nesse aspecto, adota formalmente um sistema fundado em normas jurídicas, o que se mostra bastante adequado para cumprir esses requisitos. Não é, contudo, por si só suficiente, pois, como se pode constatar, fatores de natureza até mesmo cultural exercem grande influência no respeito ao ordenamento jurídico do planejamento, o que impacta também na segurança jurídica do sistema. ${ }^{8}$

O sistema de planejamento governamental brasileiro está estruturado no ordenamento jurídico em vários diplomas legais, consoante já se pode constatar e ver-se-á ainda ao longo do trabalho, compondo um amplo e complexo sistema de normas.

6 CABRAL, Nazaré da Costa. Programação e decisão orçamental. Da racionalidade das decisões orçamentais à racionalidade económica, p. 207-210, nota de rodapé 402.

7 MONCADA, Luís S. Cabral de. Perspectivas do novo direito orçamental português, p. 54.

8 Dar-se-á ênfase, neste trabalho, dada a opção que se fez inicialmente, aos aspectos jurídicos no âmbito do direito financeiro, fazendo-se eventualmente referências pontuais, quando relevantes e necessárias, aos demais aspectos de outras áreas do conhecimento que possam se mostrar úteis ao tema abordado. 
No âmbito constitucional, podem ser identificadas com clareza as duas principais estruturas de planejamento governamental a que se fez referência no início: o planejamento econômico governamental, cujo fundamento constitucional está basicamente no art. 174 da Constituição Federal; e o planejamento orçamentário da administração pública, fundado no art. 165.

Encontram-se outras referências ao planejamento governamental no texto constitucional, especialmente no que se pode denominar planejamento governamental setorial, cujos exemplos mais claros são o Plano Nacional de Educação (art. 214) e o Plano Nacional de Cultura (art. 215, $\$ 3^{\circ}$ ). ${ }^{9}$ Planos estes que, como se pode ver em capítulos próprios dedicados a eles, contemplam funções tanto de planejamento econômico governamental (principalmente) quanto de planejamento orçamentário da administração pública. Referências também se fazem ao planejamento regional, tal como se vê no art. 174, $\$ 1^{\circ}$.

Outros diplomas legais também cuidam do assunto, destacando-se as leis que regulam, em caráter nacional, as finanças públicas, a saber, a Lei n. 4.320, de 1964, e a Lei Complementar n. 101, de 2000 - a Lei de Responsabilidade Fiscal (LRF).

Seguem-se inúmeros outros textos legais, como as leis e normas infralegais que instituem os já mencionados planos nacionais de educação e de cultura, e os que cuidam de planos e programas governamentais, especialmente os voltados a setores específicos da atuação governamental, e têm conteúdo próprio de planejamento governamental.

Isso em uma análise levando-se em consideração apenas a esfera federal de organização da administração pública.

No âmbito de Estados, Distrito Federal e Municípios, estão presentes também as leis específicas de planejamento orçamentário governamental - Plano Plurianual, Lei de Diretrizes Orçamentárias e Lei Orçamentária -, e as demais que veiculam tanto normas de planejamento econômico quanto orçamentário, ou ambas, como ocorre com os planos decenais de educação das demais esferas de governo.

A competência para legislar em Direito Financeiro, Direito Orçamentário e, também, Direito Econômico, áreas às quais estão ligadas as questões de planejamento governamental abordadas nesta obra, é da União, dos Estados e do Distrito Federal, nos termos do art. 24 da Constituição Federal. ${ }^{10}$

A Constituição prevê também o Plano Nacional da Juventude (art. 227, $₫ 8^{\circ}$, II).

10 Cabendo também aos Municípios expedir normas em matéria de direito financeiro e orçamentos, especialmente no que tange ao planejamento, visto que devem observar o disposto no art. 165 da Constituição Federal, dispondo sobre os planos plurianuais, as leis de diretrizes 
Tal como em outras áreas, o planejamento, com maior intensidade, exige uma perfeita coordenação das ações entre os diversos entes federados, tornando imprescindível que todos esses diplomas legais formem um sistema coeso.

Os aspectos jurídicos dessa coordenação normativa que deve formar esse sistema são complexos, abrangendo várias questões relacionadas com a divisão de competências, vinculações, subordinação, coordenação, cooperação e hierarquia, que se pretende abordar neste capítulo.

De início, e ratificando o já exposto, importa destacar que o "adequado funcionamento do sistema de planejamento da ação governamental construído pelo nosso ordenamento exige um conjunto coeso de normas que lhe deem sustentação", como já expressado em outra oportunidade, e a "interpretação das normas constitucionais e infraconstitucionais permite que se constate haver no Brasil um eficiente ordenamento jurídico em que se funda o planejamento do setor público". ${ }^{11}$

No âmbito do planejamento orçamentário, o sistema se funda nas três leis de natureza orçamentária a que já se fez referência anteriormente - PPA, LDO e LOA.

São leis formalmente da mesma espécie, no que tange ao processo legislativo, sendo todas leis da categoria das leis ordinárias, conforme previsto no art. 59, III, da Constituição Federal.

O mesmo ocorre com as demais leis que instituem alguns dos planos referidos no texto constitucional, como os de educação e cultura. ${ }^{12}$

Ressalve-se que, no primeiro caso - PPA, LDO e LOA, são ainda leis instituídas no âmbito de cada unidade federativa, tendo sua abrangência, em princípio, restrita ao respectivo ente da federação.

Com isso, já se pode antever que, sob o aspecto formal, são normas do mesmo patamar hierárquico, não sendo possível por esse critério reconhecer uma relação de subordinação entre elas. Entretanto, não há como prevalecer uma interpretação

orçamentárias, as leis orçamentárias e os planos setoriais, como o de educação.

11 CONTI, José Mauricio. Planejamento e responsabilidade fiscal. In: SCAFF, Fernando; CONTI, José Mauricio (Coord.). Lei de Responsabilidade Fiscal. 10 anos de vigência - questôes atuais, p. 51. E, retificando o que escrevi à época, prefiro afirmar ser um "bem construído" ordenamento jurídico, uma vez que, não obstante a adequação das normas aplicáveis, o que se tem observado, como será objeto de reflexão oportunamente, é que a prática não tem correspondido à teoria, e a não observância das normas evidencia uma baixa eficácia do ordenamento jurídico em matéria de planejamento orçamentário.

12 Embora estas, como visto no Capítulo 7 - Planejamento setorial: o planejamento orçamentário e as políticas públicas, tenham natureza e status de leis nacionais, portanto aplicáveis a todos os entes da federação. 
nesse sentido, que compromete o adequado funcionamento do sistema de planejamento orçamentário, que pressupõe um vínculo entre essas leis, de modo a assegurar que as previsões de curto prazo sejam coerentes com o que foi previamente estabelecido para o médio prazo.

Há que se identificar a correta interpretação a partir da análise sistemática do texto constitucional.

A lógica do sistema é reconhecida pelos estudiosos do tema: "O PPA foi concebido para ser o elemento central do novo sistema de planejamento, orientando os orçamentos anuais, por meio da LDO. A tríade PPA/LDO/LOA forma a base de um sistema integrado de planejamento e orçamento". ${ }^{13} \mathrm{Na}$ mesma linha, segue Weder de Oliveira, ao observar que a

"doutrina especializada costuma apresentar o modelo constitucional orçamentário como um modelo de planejamento e implementação de projetos, programas e políticas públicas calcado na ideia de pôr em movimento um sistema orçamentário condizente com a vinculação do planejamento operacional (LOA) ao planejamento tático (LDO) e deste ao planejamento estratégico (PPA), que seria o modelo racional e ideal de atuação estatal a ser perseguido". ${ }^{14}$

Pela análise do próprio texto constitucional, vê-se que existe uma relação entre essas leis que gera vínculos, imprescindíveis, como se verá, para a coesão, a eficácia e a segurança jurídica esperadas do sistema de planejamento orçamentário.

Os arts. $165, \$ 7^{\circ}$, e $166, \$ 3^{\circ}$, I, da Constituição Federal mostram que a lei orçamentária deve ser elaborada de forma compatível com o Plano Plurianual e com a Lei de Diretrizes Orçamentárias, e o art. 166, $\$ 4^{\circ}$, que a Lei de Diretrizes Orçamentárias deve se compatibilizar com o Plano Plurianual. O mesmo se extrai da Lei de Responsabilidade Fiscal, que, em seu art. 5º é claro ao reconhecer o vínculo entre as três leis: "O projeto de lei orçamentária anual, elaborado de forma compatível com o plano plurianual, com a lei de diretrizes orçamentárias e com as normas desta Lei Complementar".

No mesmo sentido, são claras as próprias normas de planejamento, como se vê do disposto no PPA federal 2012-2015, ao estabelecer que "os Programas constantes do PPA 2012-2015 estarão expressos nas leis orçamentárias anuais e nas leis de crédito adicional" (art. $\left.8^{\circ}\right)^{15}$ e que "os orçamentos anuais, compatibilizados com

PARES; VALLE, A retomada do planejamento governamental no Brasil e seus desafios, p. 232.

14 Curso de responsabilidade fiscal, p. 296.

15 Redação semelhante encontramos em outros PPA, como se pode observar do art. $3^{\circ}$ do PPA 2008-2011, a título exemplificativo: "Os programas e ações deste Plano serão observados nas leis de diretrizes orçamentárias, nas leis orçamentárias anuais e nas leis que as modifiquem”. 
o PPA 2012-2015 e com as respectivas leis de diretrizes orçamentárias, serão orientados pelas diretrizes expressas no art. $4^{\circ}$ para o alcance dos Objetivos constantes deste Plano" (art. 11).

A necessária relação de harmonia entre as três leis exige uma interpretação que estabeleça uma lógica fundada no planejamento, reconhecida inclusive em nossa Suprema Corte, em uma das poucas vezes nas quais que se pronunciou sobre o tema:

"o sistema orçamentário constitucional estabelece o convívio harmonioso de três diplomas legislativos da mais alta significação, todos de iniciativa privativa do Chefe do Poder Executivo (CR, art. 165, caput e incisos I a III): (i) o plano plurianual, (ii) a lei de diretrizes orçamentárias e (iii) a lei orçamentária anual. O fio condutor que une teleologicamente tais atos normativos (...) consiste na busca pelo planejamento e pela programação na atividade financeira do Estado, de modo a concretizar os princípios da economicidade e da eficiência na obtenção de receitas e na realização das despesas públicas, indispensáveis à satisfação dos interesses sociais por uma Administração Pública guiada pelo moderno paradigma do resultado". ${ }^{16}$

Não há dúvidas, portanto, que o sistema de planejamento orçamentário governamental de cada um dos entes federados estrutura-se com base no Plano Plurianual, cujas normas prevalecem e condicionam a Lei de Diretrizes Orçamentárias, que, por sua vez, delimita os parâmetros para a lei orçamentária.

Mas a questão não é tão simples quanto pode parecer à primeira vista.

O sistema de planejamento estruturado em normas jurídicas, com a prevalência dos planos sobre os orçamentos, é tema antigo e de intenso debate na doutrina nacional e estrangeira, e sobre o qual há que se debruçar, dada a importância das várias questões que ele suscita para o presente trabalho.

A doutrina portuguesa é rica no trato do tema, em decorrência, principalmente, da preocupação com a eficácia jurídica do planejamento, tendo em vista o sistema instituído pela Constituição portuguesa. ${ }^{17}$ A Constituição de Portugal, ao cuidar da ordem econômica, dedica o Título II (arts. 90 a 92) aos "Planos", estabelecendo um sistema que prevê planos nacionais para o desenvolvimento econômico e social, elaborados "de harmonia com as respectivas leis das grandes opçôes", a serem executados de forma descentralizada, regional e setorialmente, devendo também o orçamento do Estado ser elaborado "de harmonia com as grandes opções em matéria de planejamento” (art. 105, 2).

16 ADI n. 4.663, voto do Rel. Min. Luiz Fux.

17 Com destaque para as obras de Luís Cabral de Moncada, especialmente $A$ problemática jurídica do planeamento econômico (1985), e Perspectivas do novo direito orçamental português (2001). 
A coerência e a eficácia jurídica do sistema português, dessa forma, exigem uma primazia da Lei das Grandes Opçôes do Plano (LGOP) sobre as demais leis de planejamento, e também sobre os orçamentos, pelo reconhecimento de que a concretização das medidas previstas nos planos depende da vinculação de recursos para que estas sejam alcançadas. O raciocínio de Cabral de Moncada é claro nesse sentido ao demonstrar que o orçamento sempre esteve subordinado às opções político-econômicas do governo; trata-se de uma exposição do programa financeiro do governo, sendo esta uma das funções do orçamento - segundo ele, "novidade porém é o facto de a ordem jurídica exigir expressamente a subordinação do conteúdo da proposta governamental às grandes opções do plano fazendo do orçamento um instrumento ao serviço das finalidades gerais da política econômica que o planeamento exprime" ${ }^{18}$ E vai além, ao mostrar que a eficácia jurídica do planejamento depende da "subordinação do orçamento ao plano, única solução que tem lógica e único meio de funcionalizar a actividade financeira aos objectivos econômico-sociais do Estado". ${ }^{19}$

Acrescenta, ainda, mostrando a importância da subordinação do orçamento ao planejamento para o direito financeiro: "Em boa verdade a subordinação do orçamento à Lei das Grandes Opções do Plano, desde o momento da preparação pelo Governo do primeiro destes dois documentos, é verdadeiramente a pedra de toque do nosso direito financeiro". ${ }^{20}$

Ao discorrer sobre o tema, referindo-se em específico ao caso português, Cabral de Moncada inicialmente reconhece que o orçamento, a Lei das Grandes Opções do Plano e o plano econômico não estão no mesmo nível hierárquico, havendo uma prevalência da Lei das Grandes Opções do Plano sobre o orçamento e deste sobre o plano econômico. É claro ao afirmar que há subordinação do plano ao orçamento e deste à lei do plano. Porém, entende que "a lei das grandes opções do plano não vincula quanto ao seu conteúdo a lei parlamentar de aprovação do orçamento", uma vez que o orçamento é uma lei e, como tal, pode modificar qualquer outra, de modo que a subordinação do orçamento à lei do plano é tênue, visto poder ser alterada. Entende que "a lei do plano não tem força jurídica superior à da lei ordinária, não constituindo um terceiro gênero intermediário entre a Constituição e a lei”, para concluir, então, que há uma subordinação que decorre de um vínculo meramente político, sendo a observância pelo Governo ao elaborar o

MONCADA, Luís S. Cabral de. Perspectivas do novo direito orçamental português, p. 58.

MONCADA, Luís S. Cabral de. Perspectivas do novo direito orçamental português, p. 66.

MONCADA, Luís S. Cabral de. Perspectivas do novo direito orçamental português, p. 63. 
orçamento nada mais do que um imperativo político. $O$ que resta é uma "autovinculação" do legislador, que fica obrigado, por este imperativo político, a não emanar legislação posterior em sentido contrário. Nesse sentido, reconhece que a lei das grandes opções do plano é superior às demais, mas em função de uma "força de resistência passiva", ante essa impossibilidade de ser alterada livremente em razão dessa autovinculação política do legislador. ${ }^{21}$

As disposições constitucionais portuguesas permitem concluir que a Lei das Grandes Opções do Plano configura lei "de valor reforçado", que tem prevalência sobre as demais, nos termos do art. 112, 3, da Constituição Portuguesa, segundo a qual "Têm valor reforçado, além das leis orgânicas, as leis que carecem de aprovação por maioria de dois terços, bem como aquelas que, por força da Constituição, sejam pressuposto normativo necessário de outras leis ou que por outras devam ser respeitadas" (grifos nossos).

A evolução da Constituição portuguesa, com várias reformas ao longo dos anos, desde sua promulgação em 1976, promoveu modificações nos dispositivos relacionados com o planejamento e o orçamento, reduzindo sua relevância. E levaram a uma dualidade de interpretações no que tange ao entendimento jurídico sobre as relações entre a Lei das Grandes Opções do Plano e a Lei de Orçamento, identificando-se duas correntes doutrinárias, como explica com muita propriedade Rodrigo Faria. ${ }^{22}$

Uma corrente acolhe a interpretação de Canotilho, que reconhece haver uma vinculação jurídica, com relação de subordinação, entre a lei orçamentária e a Lei das Grandes Opções do Plano (LGOP), mas atribui a esta última "baixa densidade normativa”. Uma vez que a LGOP estabelece as orientações para a atividade financeira do Estado, a lei orçamentária deverá proporcionar os recursos para implementá-las, havendo uma vinculação jurídica; no entanto, dadas as características de generalidade da LGOP, dificilmente se poderá constatar contradiçōes entre a LGOP e o orçamento, o que lhe confere uma baixa densidade normativa.

A outra corrente, capitaneada por autores como Sousa Franco, Moncada, Jorge Miranda e Guilherme d'Oliveira Martins, considera haver não uma relação de subordinação, mas de coordenação entre os referidos instrumentos legais, que têm lógicas diferenciadas. A LGOP tem um caráter qualitativo e genérico, e a lei orçamentária é

21 MONCADA, Luís S. Cabral de. A problemática jurídica do planeamento econômico, p. 118-121.

22 FARIA, Rodrigo Oliveira de. PPA versus orçamento: uma leitura do escopo, extensão e integração dos instrumentos constitucionais brasileiros de planejamento. In: CONTI, José Mauricio; SCAFF, Fernando F. (Coord.). Orçamentos públicos e direito financeiro, p. 671-672. 
quantitativa e específica. O texto de Martins et al. evidencia isso de forma clara: "Embora o orçamento seja elaborado em harmonia com as grandes opções em matéria de planeamento (art. 105, 2), mais do que subordinação, haverá aqui coordenação ou harmonização. Aliás, sendo a lei das grandes opções qualitativa e genérica e a do orçamento quantitativa e específica, seria difícil conceber, quanto à essência de ambas, contradição jurídica, mas apenas, quando muito, diferentes lógicas político-econômicas”. ${ }^{23} \mathrm{Na}$ mesma linha, as palavras de Souza Franco, para quem a harmonização do orçamento com a Lei das Grandes Opções do Plano "exprime uma directriz incidente sobre a harmonização coerente dos respectivos conteúdos, no plano político-econômico, mas não estabelece relação de precedência ou prevalência jurídica entre as duas leis". ${ }^{24}$

Já no Brasil, a legislação que cuida das normas envolvendo o planejamento governamental permite encontrar dispositivos que levam ao reconhecimento de um vínculo de subordinação entre as leis que cuidam do tema, como mencionado anteriormente. É o que se pode depreender do disposto no art. 165, $\$ 77^{\circ}$, da Constituição Federal, quando estabelece que os orçamentos fiscal e de investimentos das empresas devem ser compatíveis com o Plano Plurianual; no art. 166, $\$ 3^{\circ}$, I, da Constituição Federal, que, ao tratar das emendas parlamentares à lei orçamentária, exige como pré-requisito para a aprovação a compatibilidade com o Plano Plurianual; no art. $5^{\circ}$ da LRF, que claramente determina que o projeto de Lei Orçamentária Anual seja elaborado "de forma compatível com o plano plurianual, com a lei de diretrizes orçamentárias e com as normas desta Lei Complementar”. Há, portanto, normas constitucionais e normas de caráter infraconstitucional, mas de natureza nacional, como as citadas, que deixam clara a relação de subordinação entre a lei orçamentária e o plano plurianual, prevalecendo este sobre aquela.

Vê-se, pelas normas vigentes aplicáveis ao caso brasileiro, que se estabelece, nas hipóteses mencionadas, vínculo jurídico entre as leis de planejamento, não sendo possível admitir existir um vínculo tão somente político, como ocorre em Portugal, no argumento defendido por Cabral de Moncada.

Mas uma análise ampla e sistemática das normas que compóem todo o sistema de planejamento governamental, especialmente no que tange ao seu aspecto orçamentário, exige uma reflexão mais acurada, que não permite concluir haver apenas uma relação de subordinação simples entre as normas.

23 MARTINS, Guilherme d'Oliveira; MARTINS, Guilherme Waldemar d'Oliveira; MARTINS, Maria d'Oliveira. A lei de enquadramento orçamental anotada e comentada, p. 115.

24 FRANCO, Antonio L. de Sousa. Finanças públicas e direito financeiro, v. I, p. 406-407. 
De fato, admitir uma relação entre as normas que veiculam o planejamento orçamentário que estabeleça um vínculo de subordinação entre o PPA, a LDO e a LOA, na forma já explicitada, e mesmo entre as normas de caráter nacional, como os planos nacionais setoriais de educação e cultura e as leis ora citadas, com prevalência destes últimos (os planos) sobre as primeiras (PPA, LDO e LOA), tendo em vista o caráter nacional dos planos, não abrange todas as possibilidades de relacionamento entre as normas mencionadas.

Várias situações exigem um aprofundamento na investigação que permita abranger todas as situações possíveis. A seguir, serão enumeradas e analisadas várias dessas situações.

\subsection{ASPECTOS TEMPORAIS | A DIVERGÊNCIA ENTRE OS PRAZOS DE VIGÊNCIA DAS LEIS DE PLANEJAMENTO}

As leis de planejamento devem estabelecer um horizonte temporal delimitado. ${ }^{25}$

A lei orçamentária, também uma lei de planejamento orçamentário, é de vigência anual, não somente no Brasil, como também em outros países do mundo. Anualidade esta que, no Brasil, corresponde ao ano civil, iniciando-se em $1^{\circ}$ de janeiro e findando em 31 de dezembro (Lei n. 4.320, de 1964, art. 34). Não é o que ocorre nos demais países, citando-se apenas para exemplificar os Estados Unidos, cujo exercício financeiro vai de $1^{\circ}$ de outubro a 30 de setembro.

O PPA federal no Brasil tem sua vigência regulada provisoriamente pelo art. 35, $\$ 2^{\circ}$, I, do Ato das Disposições Constitucionais Transitórias da Constituição Federal, que estabelece o período que vai do primeiro dia do segundo exercício financeiro do mandato presidencial até o final do primeiro exercício financeiro do mandato subsequente. Para citar exemplos recentes, o PPA federal 2012-2015, regulado pela Lei n. 12.593, de 18 de janeiro de 2012, tem vigência para o período compreendido entre janeiro de 2012 e dezembro de 2015, e o PPA federal 20162019, veiculado pela Lei n. 13.249, de 13 de janeiro de 2016, para o período de janeiro de 2016 até dezembro de 2019; o PPA 2020-2023, para o período de janeiro de 2020 a dezembro de 2023.

Estados e municípios preservam a regra da vigência do PPA, alterando, eventualmente, apenas a data de apresentação da proposta.

No Estado de São Paulo, o PPA 2016-2019, regulado pela Lei Estadual n. 16.082, de 28 de dezembro de 2015, tem sua vigência estabelecida para o período

25 Conforme já abordamos no Capítulo 3 - Planejamento, orçamento e plurianualidade. 
equivalente do PPA federal 2016-2019, o mesmo ocorrendo com os respectivos PPAs 2020-2023.

Ocorre que, no Brasil, os mandatos dos governantes, o critério utilizado pela legislação para estabelecer o período de validade do PPA, não são coincidentes. Na União e nos Estados coincidem os mandatos, o mesmo não ocorrendo com os municípios.

Tanto assim que, no Município de São Paulo, o PPA 2010-2013, regulado pela Lei Municipal n. 15.090, de 29 de dezembro de 2009, vale para o período de janeiro de 2010 até dezembro de 2013, e o seguinte (Lei n. 15.949, de 30 de dezembro de 2013), para o período de janeiro de 2014 a dezembro de 2017.

O Plano Nacional de Educação, em sua dimensão temporal, é decenal, por expressa disposição constitucional, e o Plano Nacional de Cultura, plurianual, sem especificação de prazo, tendo sido o primeiro elaborado para o período de dez anos.

O Plano Nacional de Educação (PNE) teve sua primeira versão na forma da Lei n. 10.172, de 9 de janeiro de 2001, para vigorar por dez anos, a partir da data da publicação, que ocorreu em 10 de janeiro de 2001 - portanto, no período de 10 de janeiro de 2001 até 9 de janeiro de 2012. E o art. 20 da lei determina que Estados, Distrito Federal e Municípios elaborem, com base no PNE, seus planos decenais correspondentes - o que, em ocorrendo, fará com que tenham datas de início e término diferentes das do plano nacional.

O Plano Nacional de Cultura (PNC) teve sua primeira edição veiculada pela Lei n. 12.343, de 2 de dezembro de 2010, com duração de dez anos, entrando a lei em vigor na data da publicação, o que ocorreu em 3 de dezembro de 2010, valendo, pois, para o período de 3 de dezembro de 2010 a 2 de dezembro de 2020. No caso do PNC, a adesão é voluntária por parte de Estados e Municípios, que se obrigam a elaborar seus planos, com duração decenal, em até um ano após a assinatura do termo de adesão voluntária ao PNC $\left(\operatorname{art.} 3^{\circ}, \S 3^{\circ}\right)$. Isso evidentemente gerará uma grande diversidade de prazos de vigência dos planos de cultura da União, dos Estados, do Distrito Federal e dos Municípios.

Do exposto, fica claro que o período de vigência das diversas leis que regulam o planejamento dos entes da federação não coincide, o que evidentemente gera transtornos, como bem observado por Osvaldo Sanches:

"Outro problema sério nos processos atuais de planejamento do setor público é a falta de concatenação dos prazos relativos à elaboração e apreciação dos vários instrumentos formais/legais, gerando falta de sincronia entre os instrumentos de planejamento e orçamento da União (PPA, LDO e LOA) e entre tais instrumentos e os seus similares nos estados e municípios. No primeiro caso, pelo fato de a LDO preceder o PPA 
e, no segundo, pela adoção dos mesmos prazos para encaminhamento dos projetos respectivos pelo Poder Executivo e para a apreciação pelo Poder Legislativo, com todas as complicações apontadas nos itens precedentes. Em razão disso, as decisões de política pública, expressas pelos planos e orçamentos, chegam sempre atrasadas aos possiveis parceiros públicos e interessados" (grifos do original). ${ }^{26}$

Vejamos o caso do PNE, que é nacional, e, portanto, deve ser observado por todos os entes da federação. A primeira edição vigorou pelo período de 2001 a 2011, abrangendo os seguintes PPA federais: PPA 2000-2003 (parcialmente); PPA 2004-2007 (inteiramente); e PPA 2008-2011 (inteiramente), o mesmo ocorrendo com os PPA estaduais. No âmbito municipal, estiveram vigentes os PPA 19982001 (parcialmente), 2002-2005 (inteiramente), 2006-2009 (inteiramente) e 2010-2013 (parcialmente). Situação semelhante ocorre com o PNE vigente para o período de 2014 a 2024.

Considerando o federalismo cooperativo acolhido pelo ordenamento jurídico brasileiro, é imprescindível para o adequado funcionamento do planejamento orçamentário governamental uma coordenação entre todas essas leis.

$\mathrm{O}$ art. 165, $\$ 4^{\mathrm{o}}$, da Constituição Federal dispõe que "os planos e programas nacionais, regionais e setoriais previstos nesta Constituição Federal serão elaborados em consonância com o plano plurianual”. Ressalte-se que, nessa hipótese, a Constituição Federal faz referência ao PPA federal, pois, embora a redação do texto tenha natureza nacional, em face da referência aos planos nacionais, regionais e setoriais, elaborados em âmbito nacional, não há como reconhecer que a referência ao PPA possa ser extensível ao PPA de todas as esferas de governo, por incompatibilidade evidente em se submeter um plano nacional aos planos plurianuais de todos os entes da federação. Ademais, em consonância com o art. 21, IX, da Constituição Federal, que atribui competência à União para elaborar e executar planos nacionais e regionais de desenvolvimento econômico e social, vê-se que o artigo mencionado explicita essa competência da União, reforçando a interpretação que a menção ao PPA se refere ao federal.

Esse artigo, cujo texto é da Constituição publicada em sua primeira versão, sendo, portanto, do texto original, não foi objeto de emendas que tenham promovido qualquer alteração. Seu conteúdo, por conseguinte, deve ser interpretado de forma que se extraia a correta interpretação, o que, como se verá, não é tarefa fácil. Embora não se observem questionamentos doutrinários ou judiciais, há que se fazer

26 SANCHES, Oswaldo Maldonado. Alguns imperativos da reforma orçamentária. Boletim de Desenvolvimento Fiscal, p. 59. 
um esforço que permita dar-lhe sentido de forma compatível com o sistema constitucional de planejamento e orçamento. Isso porque, em uma primeira leitura, já é possível observar que a redação determina que planos nacionais sejam elaborados em consonância com o plano plurianual, que é, nesse caso, lei federal, como já exposto - e, portanto, aplicável à administração pública federal -, o que, à primeira vista, não se compatibiliza com a organicidade e lógica do sistema constitucional de planejamento e orçamento.

No que tange ao aspecto temporal, a análise do prazo de vigência das leis de planejamento anteriormente citadas para ilustrar o ora exposto mostra bem a dificuldade em estabelecer um ordenamento jurídico coeso se admitida a relação entre as leis por um vínculo de subordinação ou hierarquia.

Ao observar literalmente o disposto no art. $165, \$ 4^{\circ}$, da Constituição Federal, o PNE 2001-2011 teria de ser elaborado em consonância com o PPA federal 20002003, que estava em vigor quando foi publicada a lei do PNE. No entanto, o referido PPA expirou sua validade em dezembro de 2003, e o PNE continuou vigente, uma vez que só se encerrou em janeiro de 2012. Em janeiro de 2004, estaríamos na situação em que o PNE 2001-2011 mantinha-se em vigor, mas, expirada a vigência do PPA 2000-2003, passaria a vigorar o PPA 2004-2007. Admitir que o PPA 20042007 possa se sobrepor ao PNE 2001-2011, em se acolhendo uma interpretação literal do art. 165, $\$ 4^{\circ}$, da Constituição Federal, é incoerente sob vários aspectos.

Primeiro, porque mitiga - para não dizer, anula - a segurança jurídica da lei do PNE. Qual a lógica de elaborar uma lei nacional de planejamento com duração decenal que se submeterá a outra, a ser elaborada futuramente, estando ainda dentro de seu prazo de vigência? É evidente que isso não faz nenhum sentido. Segundo, não se pode esquecer que a lei do PNE é nacional, e, portanto, aplicável a todos os entes da federação. Sendo assim, como submeter a lei do PNE ao PPA federal, cuja vigência tem prazo inferior, e admitir que o PPA federal subsequente possa alterá-la se o PNE estabeleceu diretrizes para todos os entes da federação, enquanto o PPA tem alcance no âmbito da administração pública federal? Note-se ainda que, no exemplo ilustrativo citado, ao final da vigência do PPA federal 2000-2003, elaborou-se o PPA federal 2004-2007, quando vigente o PNE - de âmbito nacional -, vigência esta que se estenderia por todo o prazo do referido PPA. Sendo o PPA aplicável à administração federal, e elaborado sob a vigência de um plano nacional, a lógica é evidente no sentido de que, no setor abrangido pelo PNE, que é a área da Educação, o PPA federal é quem deve observar, para o período, no que for cabível, as disposições do PNE. Como resolver as questôes colocadas exige respostas que não são simples, mas permite reconhecer não haver como estabelecer um vínculo de subordinação linear 
entre essas leis, e não há como interpretar literalmente o que dispõe o art. $165, \S 4^{\circ}$, da Constituição Federal, cuja racionalidade só se fará presente se admitida uma interpretação que leve em consideração a lógica do sistema como um todo.

Nesse caso, não é possível admitir uma relação de subordinação e hierarquia, mas tão somente de coordenação e integração. Isso porque são planos e programas nacionais, o que evidentemente os torna aplicáveis a todos os entes da federação, e os planos plurianuais são elaborados por e para cada ente da federação, por leis próprias - federais, estaduais, distrital e municipais. Além disso, nos casos em que os planos apresentem descoincidência temporal por qualquer razão (é o caso dos decenais, que ultrapassam o período dos planos plurianuais, atualmente quadrienais), haverá vigência dos planos para períodos posteriores ao final do prazo estabelecido pelo plano. Sendo assim, ainda que, em um primeiro momento, em obediência literal ao texto constitucional expresso, os planos regionais e setoriais sejam elaborados observando o plano plurianual (que, na hipótese, é o federal), findo o prazo deste teremos vigente um plano de caráter nacional que condicionará a elaboração do plano plurianual sucessivo. Há que se considerar também o aspecto material, uma vez que, nessa hipótese, poderá haver coincidência parcial, porém não necessariamente, bem como de abordagem, no estabelecimento de pontos comuns, como eventuais diretrizes e metas, que podem ter impacto orçamentário a ser respeitado pelos planos plurianuais.

Nesse sentido, vale retomar o já citado trabalho de Rodrigo Faria, que propõe reconhecer uma relação horizontal de coordenação e integração entre as normas de planejamento. Destaca inicialmente que "plano e orçamento cumprem funções distintas, muito embora complementares", sendo o plano plurianual indicativo, enquanto a lei orçamentária discrimina todas as receitas e despesas, sendo ampla e exaustiva. E os planos e programas nacionais, regionais e setoriais se diferenciam dos planos plurianuais tanto pelo aspecto temporal (têm duração diferente, como o Plano Nacional de Educação, de dez anos) quanto pelo material (referem-se a setores específicos da atividade governamental), de modo que apresentam lógica e conteúdo diferenciados, evidenciando que o legislador não pretendeu estabelecer entre eles uma relação de obediência e hierarquia. Defende a tese de que existe "uma relação horizontal entre os instrumentos constitucionais brasileiros de planejamento e orçamento, pautada pela coordenação e integração", tendo em vista que o planejamento normativo é insuficiente para dar conta de um ambiente instável e volúvel, há distintos campos de competência abrangidos pelos diversos instrumentos de planejamento e orçamento, não existe hierarquia entre as leis de planejamento e orçamento, e "a compatibilidade exigida pelo texto constitucional se resolve no 
sentido de relaçôes de coordenação e articulação entre campos materiais distintos, muito embora indiscutivelmente complementares". Conclui sua argumentação mostrando que "os diversos instrumentos normativos brasileiros de planejamento e orçamento integram-se por meio de relaçôes horizontais de coordenação e articulação, de modo a assegurar a compatibilidade exigida pelo texto constitucional", não havendo "hierarquia entre tais leis, visto que a cada uma previu o legislador constituinte um campo próprio e específico de competência, muito embora complementares, requerendo uma ação devidamente coordenada e articulada por parte do Poder Público, com vistas ao alcance das finalidades pretendidas". ${ }^{27}$

São argumentos extremamente consistentes e apontam no caminho certo, uma vez que a interpretação sistemática do texto constitucional não permite outra conclusão que não compreenda uma necessária relação de coordenação e integração entre as leis e os demais instrumentos normativos de planejamento governamental.

É evidente, como já mencionado anteriormente em texto de minha autoria, em referência às três leis citadas, a "necessidade de coordenação entre elas, de modo que as previsões do plano plurianual condicionem a elaboração da lei de diretrizes orçamentárias, que por sua vez delimita os parâmetros a serem seguidos pela lei orçamentária anual". ${ }^{28}$

Ver-se-á, contudo, que essa relação de coordenação e integração não prescinde, ainda que de forma não generalizada, reconhecer haver, em determinadas situações, relações de hierarquia e subordinação. O orçamento está, em certas circunstâncias, necessariamente subordinado ao planejamento, destaca Premchand. ${ }^{29} \mathrm{O}$ sistema de normas de planejamento orçamentário governamental é extremamente complexo, composto de várias espécies de normas, com abrangências, funções, lógicas e conteúdos que são por vezes distintos, e também se complementam, que só podem formar um todo necessariamente coeso se interpretadas de forma a reconhecer haver entre elas uma relação que é essencialmente de coordenação e integração, sem prejuízo de haver também relações de hierarquia e subordinação, como se pretende demonstrar.

Há várias normas que se relacionam em situações diversas, sendo conveniente a análise das muitas hipóteses, a fim de compreender as possíveis interpretações que comporão esse sistema coeso.

27 FARIA, Rodrigo Oliveira de. PPA versus orçamento: uma leitura do escopo, extensão e integração dos instrumentos constitucionais brasileiros de planejamento, p. 681-688.

28 CONTI, José Mauricio. Planejamento e responsabilidade fiscal, p. 51.

29 PREMCHAND, A. Government budgeting and expenditure controls. Theory and practice, p. 183: "The budget in such circumstances is necessarily subordinate to the framework of planning". 
O planejamento orçamentário governamental propriamente dito, constituído, em todos os entes da federação, pelas leis do plano plurianual, pelas diretrizes orçamentárias e pelo orçamento, compreende um sistema jurídico de normas que exigem coordenação, integração $e$ também hierarquia e subordinação.

O Plano Plurianual, lei ordinária como as demais, tem a função constitucional de estabelecer as diretrizes, objetivos e metas da administração pública para as despesas de capital e outras delas decorrentes e para os programas de duração continuada (art. 165, $\$ 1^{\circ}$, da CF), e conter a previsão de investimentos cuja execução ultrapasse um exercício financeiro (art. 167, $\$ 1^{\circ}$, da CF). Não há regulamentação infraconstitucional de caráter nacional sobre o exato conteúdo do PPA, gozando os entes federados de liberdade para organizá-lo. Plausíveis as teses segundo as quais o PPA deve conter previsões de caráter predominantemente indicativo e com maior grau de generalidade, sem configurar verdadeiros "orçamentos de médio prazo", com informações detalhadas de ações governamentais acompanhadas de dotações com valores exatos do montante que se pretende gastar no período para o qual foi elaborado. Não há, contudo, qualquer impedimento de que tenham essa conformação, que, embora criticável sob vários aspectos, como o excessivo engessamento, eventualmente incompatível em muitos casos com a dinâmica econômica e social, mostra-se mais focado, claro e transparente com relação aos rumos da administração pública, facilitando o controle institucional e social do gasto público. Nessa

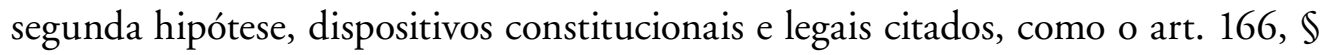
3, I, da Constituição Federal, e o art. $5^{\circ}$, caput, da LRF, são muito claros e somente permitem concluir haver uma primazia do Plano Plurianual sobre a Lei de Diretrizes Orçamentárias e o orçamento anual, que, necessariamente, terão de ser elaborados dentro dos limites e atendendo às diretrizes neles estabelecidas, o que configura uma relação de subordinação, que não atingirá sempre e necessariamente todas as situações tratadas pelas referidas normas. Mas impede a ocorrência de discrepâncias e incompatibilidades, que, se houver, levarão ao reconhecimento de inconstitucionalidade ou ilegalidade da norma conflitante, devendo ser considerada a prevalência de uma sobre a outra, nos termos mencionados.

\subsection{A INCOMPATIBILIDADE DOS PRAZOS DO PPA, DA LDO E DA LOA NO PRIMEIRO ANO DE MANDATO}

A dificuldade em estabelecer um sistema que tenha em conta uma vinculação entre as leis orçamentárias no Brasil, de modo a considerar haver uma subordinação e hierarquia entre elas, mostra-se presente em outras situações, como nos casos em que há incongruências nos prazos de vigência das referidas leis, inviabilizando 
um ordenamento jurídico com coesão e lógica, exigindo, assim, uma interpretação que possa compatibilizar as normas do sistema.

A vigência do PPA no primeiro ano de mandato é um caso ilustrativo que evidencia isso de forma bastante clara.

A Constituição Federal estabelece, para o PPA federal, ${ }^{30}$ "até a entrada em vigor da lei complementar a que se refere o art. 165, $\$ 9$, I e II", que "o projeto do plano plurianual, para vigência até o final do primeiro exercício financeiro do mandato presidencial subsequente, será encaminhado até quatro meses antes do encerramento do primeiro exercício financeiro e devolvido para sanção até o encerramento da sessão legislativa” (art. $35, \$ 2^{\circ}$, I, do ADCT).

Ocorre que, neste ano a que se fez referência - o primeiro ano do mandato -, a Lei de Diretrizes Orçamentárias federal segue a regra geral que se aplica todos os anos, na forma do art. $35, \$ 2^{\circ}$, II, do ADCT, segundo a qual o projeto "será encaminhado até oito meses e meio antes do encerramento do exercício financeiro e devolvido para sanção até o encerramento do primeiro período da sessão legislativa".

Sendo assim, no primeiro ano do mandato, teremos a seguinte situação: o PPA, cuja vigência iniciar-se-á no início do segundo ano de mandato, terá sua proposta apresentada no segundo semestre, quando já estiver em vigor a LDO, aprovada no primeiro semestre do ano em questão, e, além de orientar a elaboração da lei orçamentária anual (cujo prazo de apresentação, tramitação e aprovação é coincidente com o PPA - ADCT, art. 35, $\$ 2^{\circ}$, III), terá disposições válidas para o mesmo período do PPA, entre as quais se chama a atenção para o anexo de metas fiscais.

Vê-se tratar de hipótese em que, admitindo-se uma vinculação entre as leis que estabeleça uma subordinação da LOA à LDO e destas ao PPA, não será possível viabilizar isso no primeiro ano do mandato, dada a precedência temporal da LDO sobre o PPA e da simultaneidade do PPA com a LOA.

Como já escrito anteriormente em texto de minha autoria,

"a apresentação do projeto de lei do plano plurianual deverá ser feita pelos próximos prefeitos no final do ano que vem (2013), para vigorar a partir do início do exercício subsequente (2014). No entanto, a lei de diretrizes orçamentárias, que deverá guardar coerência com o plano plurianual, será elaborada no primeiro semestre do ano que vem (2013), condicionando a elaboração da lei orçamentária anual, a ser aprovada no

30 Em dispositivo que tem sido reconhecido como de natureza federal, admitindo-se que os demais entes da federação estabeleçam datas diferentes no que tange à apresentação da proposta e respectiva aprovação, mantendo-se o período quadrienal de vigência. 
final de 2013 para vigorar em 2014, e contendo dispositivos capazes de regular a execução orçamentária, que ocorrerá ao longo de 2014. Desta forma, no exercício de 2013 a LDO será elaborada antes do plano plurianual, e a lei orçamentária, concomitantemente ao plano plurianual, e todas produzirão efeitos em 2014, tornando evidentemente inviável a perfeita coerência entre elas. Há que se pensar em uma solução legislativa para resolver esta distorção" ${ }^{31}$

Especialistas no tema já há muito têm alertado para a necessidade de ajustes. "Outro problema sério nos processos atuais de planejamento do setor público é a falta de concatenação dos prazos relativos à elaboração e apreciação dos vários instrumentos formais/legais, gerando falta de sincronia entre os instrumentos de planejamento e orçamento da União (PPA, LDO e LOA) e entre tais instrumentos e os seus similares nos estados e municípios", afirma Osvaldo Sanches, e mostra que a observância dos prazos estabelecidos pelo art. 35 do ADCT, gera "a prática do PPA ser apreciado, todos os anos, 'a reboque' dos projetos de LDO e LOA, em evidente violação à ordem instituída pela Constituição. Tal ordem, claramente expressa na Lei Maior, seria a de o PPA servir de guia às LDOs e LOAs; e de a LDO, fundada no PPA, guiar a formulação da LOA e fixar as prioridades da alocação". Em seguida, apresenta sugestões de alteração na cronologia de elaboração e apreciação dos PPA, das LDO e das LOA,

"de modo a restabelecer a ordem lógica prevista no texto constitucional (e distorcida pelo ADCT) e a assegurar que não apenas cada uma dessas leis seja elaborada sob a base apropriada pela que a antecede, mas, também, que os estados possam cumprir essa atividade com o prévio conhecimento do conteúdo das normas federais, e que os municípios o façam com o prévio conhecimento das normas das esferas federal e estadual antes do final do prazo para a formalização de seus instrumentos”.

O que permitiria, assim, a desejável ação articulada entre as várias esferas de governo. ${ }^{32}$

No mesmo sentido, manifesta-se Weder de Oliveira, expondo a falta de sincronia de prazos das leis orçamentárias no primeiro ano de mandato e mostrando os ajustes feitos por meio das LDO (como ocorreu nos anos de 1999 - LDO para 2000, 2003 - LDO para 2004, e 2007 - LDO para 2008) e os projetos de lei em andamento com as propostas de novas cronologias de prazos, na tentativa de resolver esse problema que, até o momento, reputa ser insolúvel. ${ }^{33}$

31 CONTI, José Mauricio. No primeiro ano de mandato não se cumprem promessas. Levando o direito financeiro a sério, p. 161-164.

32 SANCHES, Oswaldo Maldonado. Alguns imperativos da reforma orçamentária, p. 59.

33 OLIVEIRA, Weder de. Curso de responsabilidade fiscal, p. 295-303. 
Correta a posição; trata-se de situação que apresenta como única solução satisfatória a alteração legislativa de forma a compatibilizar referidas normas de modo que os prazos de cada uma sejam estabelecidos a fim de permitir a observância das competências próprias de cada uma e do vínculo que as une formando um sistema de planejamento e orçamento que guarde coerência e lógica dentro do sistema. Um aperfeiçoamento nesse sentido é proposto no projeto de Lei n. 229, de 2009, em tramitação para suceder a Lei n. 4.320, de 1964, em que há prazos iguais para o PPA e a LDO. ${ }^{34}$

No entanto, diante do quadro exposto, estando a legislação de planejamento orçamentário em vigor desde 1988, e sem previsão concreta de alteração a curto prazo, não obstante os vários projetos de lei em tramitação visando a regulamentar o art. $165, \$ 9^{\circ}$, da CF, há que se interpretar o ordenamento jurídico com as normas postas.

Nessa hipótese, clara fica a inviabilidade da interpretação que admita uma relação hierárquica linear entre as leis da forma preconizada pela lógica que se pretendeu estabelecer pela sistemática construída na Constituição Federal.

A única solução possível necessariamente passa pela interpretação sistemática que leve em consideração a harmonia do ordenamento pela coordenação entre as normas de planejamento, da forma como delineada nos itens anteriores, analisando-se as competências específicas de cada uma das leis, para que cada hipótese de inconsistência entre elas possa ter sua controvérsia dirimida pela análise conforme esses parâmetros, até que a solução legislativa possa ser adotada e mitigar as possibilidades de conflito.

\subsection{INCOMPATIBILIDADES INTRAGOVERNAMENTAIS COM AS NORMAS DE PLANEJAMENTO}

O PPA, como principal instrumento jurídico de planejamento orçamentário governamental, relaciona-se com vários instrumentos jurídicos de planejamento próprios de outros órgãos governamentais, incluindo os Poderes e as instituições independentes, as autarquias, as fundações e os demais órgãos nos quais se desdobra a administração pública direta e indireta.

Muitos deles elaboram e seguem seus próprios planejamentos, materializados em instrumentos jurídicos diversos, com maior ou menor reflexo orçamentário, o

Ainda que não seja uma solução absolutamente satisfatória. No Projeto de Lei n. 229/2009, o PPA deve ser proposto até 15 de abril (art. 15) e devolvido para sanção até 15 de julho (art. 19). Os mesmos prazos são fixados para a LDO (arts. 24 e 27, respectivamente). 
que exige uma compatibilidade entre os referidos planejamentos e o PPA, e vice-versa. No âmbito do Poder Executivo federal, embora a legislação preveja que, ao realizar o planejamento próprio, deve-se fazê-lo em obediência aos programas gerais, setoriais e regionais de duração plurianual, ${ }^{35}$ são muitas as situações em que essa determinação não se mostra suficiente para evitar conflitos.

Trata-se de compatibilização complexa, especialmente pela multiplicidade de fatores que se inter-relacionam. Muitas vezes, há planejamentos que envolvem órgãos específicos, mas que dependem de outros órgãos para concretizarem seus objetivos e metas; em outras oportunidades, sendo o planejamento setorial - tema objeto de abordagem em item específico -, abrange vários órgãos. Noutras vezes, e destacam-se os Poderes nesse aspecto, especialmente o Poder Judiciário (também objeto de estudo em item próprio), há que se respeitar a independência que lhes é constitucionalmente assegurada, o que exige a compatibilização do PPA - que é um planejamento de toda a administração pública de determinada esfera de governo - com o planejamento de um órgão que representa um poder independente que integra referida administração.

Há que se considerar, em todas essas situações, a não coincidência de prazos, fazendo com que, na maior parte dos casos, o prazo de vigência do PPA não coincida com os prazos de planejamento há pouco referidos, criando situações em que se finda o prazo de vigência do PPA sem que os demais planejamentos, que muitas vezes dele dependem, continuem vigentes, exigindo que se estabeleçam mecanismos que assegurem coesão, compatibilidade e segurança jurídica para todo esse sistema.

Nessas hipóteses, várias são as situações, e diversas são as soluções, algumas das quais objeto de análise em itens específicos voltados ao tema sob outro enfoque.

Em sendo o órgão planejador subordinado a outro - é o caso, por exemplo, de um órgão integrante do Poder Executivo Federal -, e sendo o PPA federal responsável pelo planejamento de toda a Administração Pública federal, que, portanto, inclui o Poder Executivo Federal, sua norma planejadora estará subordinada ao PPA federal, devendo com ele ser compatível. Evidentemente que, em havendo maior detalhamento, o que é de se esperar em uma norma específica, este deverá guardar relação de coerência e compatibilidade com o PPA.

Há que se respeitar também a hierarquia formal das normas, de modo que, tendo sido a norma planejadora exarada por ato de órgão da administração - por

35 Decreto-lei n. 200, art. 15: "A ação administrativa do Poder Executivo obedecerá a programas gerais, setoriais e regionais de duração plurianual, elaborados através dos órgãos de planejamento, sob a orientação e a coordenação superiores do Presidente da República”. 
exemplo, como um decreto -, cujo fundamento de validade é uma lei planejadora, como o PPA, com este último também deverá a primeira guardar relação de lógica e coerência, uma vez respeitados os limites de atribuição de cada um.

Situações mais complexas são observadas nos casos em que se colocam em conflito órgãos dotados de independência constitucionalmente assegurada, como é o já citado caso do Poder Judiciário, que tem autonomia administrativa e financeira expressamente previstas no texto constitucional.

Nessas hipóteses, embora o Poder Judiciário - para exemplificar com o caso mais emblemático - integre o Estado, cujo planejamento orçamentário de médio prazo vem expresso no PPA do respectivo ente da federação, sua autonomia financeira lhe confere a prerrogativa de elaborar seu próprio orçamento (art. 99, $\$ 1^{\circ}$, da $\mathrm{CF}$ ). Ainda que o texto constitucional seja omisso com relação ao PPA, é decorrência da lógica e coerência do sistema que tal prerrogativa estenda-se também ao Plano Plurianual, de modo que cabe ao Poder Judiciário, da mesma forma, elaborar a parte que lhe cabe no plano plurianual do respectivo ente da federação, o que impediria de haver incompatibilidades nesse aspecto. No entanto, há sempre a possibilidade de surgirem conflitos.

Havendo item específico para abordar a questão, ao tratar do "planejamento intragovernamental", ficam lançadas por ora algumas questôes iniciais, que serão objeto de análise oportunamente no Capítulo 6 - Planejamento orçamentário intragovernamental e o Poder Judiciário.

\subsection{INCOMPATIBILIDADES SETORIAIS COM OS PRAZOS DE NORMAS DE PLANEJAMENTO}

Outra importante questão que propicia a ocorrência de múltiplas possibilidades de incompatibilidades e conflitos decorre da setorialização da administração pública e das respectivas políticas públicas e ações governamentais.

Há, portanto, áreas de atuação governamental que procuram corresponder a órgãos da administração, mas a complexidade da realidade não permite que haja sempre uma coincidência entre eles. $\mathrm{O}$ orçamento público - e as demais leis orçamentárias de forma geral - procuram espelhar todos os aspectos da administração, o que se pode constatar pelos diversos demonstrativos em que se desdobram. Assim é que a Lei Orçamentária Anual brasileira contém as classificações das despesas públicas pelos critérios funcional, institucional, econômico e programático, cada um deles atendendo a determinado aspecto que se pretenda tornar claro sobre as despesas públicas. 
Evidentemente, não se trata de tarefa simples, nem os resultados da classificação se apresentam precisos, dada a realidade, ampla e multifacetada, não permitindo que se possam inserir todas as situações em classificações precisas e detalhadas, o que se refletirá no aspecto orçamentário e, por consequência imediata, no planejamento orçamentário governamental.

Assim é que há no orçamento áreas como a da Saúde, que se materializam na peça orçamentária na função saúde, com órgãos especificamente a ela voltados, como o Ministério da Saúde (na esfera federal), a Educação, com a função Educação e o Ministério da Educação, e tantos outros. De outra parte, áreas como a de Proteção à Criança e ao Adolescente não estão necessariamente representadas em uma função, nem existem no mais das vezes órgãos especificamente a elas destinados. Há, no entanto, muitas políticas públicas para atender às suas finalidades, cujas dotações podem estar por vezes classificadas na área da Saúde, outras na de Educação, e também utilizando recursos de várias áreas simultaneamente.

Planejar políticas públicas multissetoriais, como o exemplo citado, envolve a construção de programas e respectivas ações governamentais, com as respectivas dotações, de modo a considerar aspectos de transversalidade, que têm sido desenvolvidos mais recentemente, e abordados com maior ênfase no penúltimo Plano Plurianual federal (PPA 2012-2015), com vistas a operacionalizá-las de forma mais clara e segura, exigindo a elaboração de normas que se tornem compatíveis em todos os aspectos.

O assunto será abordado mais à frente no Capítulo 7 - Planejamento setorial, ao tratar do tema do planejamento setorial, em que se pretende analisar essas questões, bem como aquelas relacionadas com o planejamento de áreas específicas da Administração Pública.

\subsection{LEIS DE PLANEJAMENTO E A QUESTÃO FEDERATIVA - O PLANEJAMENTO ORÇAMENTÁRIO INTERFEDERATIVO}

Outra relação entre normas de planejamento que merece atenção e análise mais aprofundada abrange a questão federativa envolvida nas leis de planejamento, com destaque para os planos plurianuais.

O tema será tratado a seguir no Capítulo 5 - Federalismo e planejamento orçamentário intergovernamental, voltaremos a ele dando maior ênfase no aspecto específico dos planos plurianuais brasileiros.

O sistema de planejamento orçamentário da administração pública, como já mencionado, é organizado essencialmente no âmbito de cada unidade federativa, por meio do PPA, da LDO e da LOA, todas leis ordinárias, editadas pelos referidos 
entes. Sendo o Brasil um país em que predomina o federalismo cooperativo, necessariamente todas essas normas deverão formar um sistema lógico e coerente, uma vez que parcelas significativas das mais importantes políticas públicas deverão ser compartilhadas, o que inclui o aspecto financeiro, exigindo que as leis de planejamento orçamentário as contemplem.

No sistema de planejamento orçamentário, portanto, é fundamental que haja uma racionalidade na ação governamental, que envolve a relação jurídica entre PPA de esferas federativas distintas, sobretudo para aquelas ações governamentais operacionalizadas com recursos de outros entes federativos.

No regime de federalismo fiscal cooperativo brasileiro, inúmeras políticas públicas são implementadas e executadas por mais de um ente federado, e com duração plurianual. Necessária, portanto, a inserção delas em um sistema de planejamento da ação governamental plurianual que seja abrangente para todos os entes da federação envolvidos. E nem todas as áreas de atuação governamental têm previstas leis de planejamento governamental setorial de âmbito nacional que possam uniformizar as políticas públicas do setor e apresentar prevalência sobre as leis de planejamento próprias de cada ente federado, tal como ocorre com a educação, que tem no PNE uma lei nacional de planejamento que cumpre, ao menos em parte, essa função. ${ }^{36}$

Nas hipóteses em que há leis de caráter nacional estabelecendo as diretrizes para o planejamento, a organização de um sistema coeso é um pouco mais simples, o que ocorre setorialmente, em face de legislações específicas, como é o caso já mencionado da Educação e da Cultura, entre outras. Nessas hipóteses, permite-se identificar uma relação vertical entre as normas de planejamento orçamentário.

Tendo em vista que o tema já é objeto de análise própria no estudo do planejamento orçamentário setorial, desnecessário aprofundar-se neste momento.

Questão mais complexa se dá quando se trata da relação horizontal entre normas de planejamento orçamentário no âmbito federativo, diante de uma necessária cooperação para implementação de políticas públicas em regime cooperativo.

Esclarecemos que cumpre apenas em parte porque a função do PNE não é de delimitar precisamente o planejamento orçamentário do setor, como se esclarece no tópico específico destinado a tratar do tema. O PNE, em cumprimento de sua função de planejar o setor de Educação, também - mas não exclusiva nem necessariamente - trata das questões orçamentárias, mas dele não se exige a especificação de todos os detalhes sob esse aspecto. Sendo assim, faz-se necessário que as leis de planejamento orçamentário observem o PNE naquilo que houver disposição tratando do assunto, o que não impede de, eventualmente, haver temas orçamentários ligados ao setor de educação não especificamente regulados pelo PNE, caso em que haverá maior liberdade do legislador dispor sobre as questôes orçamentárias com ele relacionadas. 
O sistema de planejamento orçamentário governamental estrutura-se, como já explicitado, essencialmente fundado no PPA, na LDO e na LOA de cada ente federado. Sendo assim, toda política pública de duração plurianual que envolva mais de um ente da federação deverá, em seus reflexos financeiros, estar contemplada nas leis orçamentárias de cada ente a ela integrado, incluindo os respectivos PPA. É fácil perceber as dificuldades a serem enfrentadas para estabelecer uma coordenação entre as leis que permita formar um todo coeso, com uniformidade no tratamento das políticas públicas cujo financiamento e execução dependam da colaboração de mais de uma esfera de governo, tendo em vista especialmente a autonomia dos entes federados que deve ser respeitada, incluindo a competência legislativa para elaboração e execução dos PPA.

Isso porque, sendo leis ordinárias próprias de cada ente federado, não existe formalmente hierarquia entre elas, não havendo, em princípio, como fazer prevalecer um planejamento sobre o outro.

$\mathrm{Na}$ falta de lei nacional regulando o setor ou, eventualmente, a política pública em questão, há que se viabilizar juridicamente a coordenação entre os PPA.

Não existindo forma de assegurar estar a política pública contemplada nos PPA (e LDO e LOA) de todos os entes envolvidos, e sendo a sustentação financeira indispensável para a viabilização da política pública em questão, à toda evidência ficarão comprometidas a segurança jurídica do planejamento e a consequente implementação e execução da referida política pública. Em outras palavras, inviabilizar-se-á, ou, ao menos, terá poucas garantias do ordenamento jurídico, qualquer política pública de duração plurianual operacionalizada no âmbito do federalismo cooperativo, que exija a participação conjunta de mais de um ente federado. E aceitar uma sustentação meramente política, sem apoio no ordenamento jurídico, é evidentemente frágil, comprometendo toda a segurança jurídica que se espera da atuação do Estado em busca de seus objetivos.

O aprofundamento no estudo dessa questão invariavelmente passa pela análise da relação que se estabelece no âmbito federativo entre as leis de planejamento das várias esferas de governo, especialmente o PPA, principal instrumento condutor do planejamento orçamentário de médio prazo da administração pública para cada um dos entes federados, vistos isoladamente.

Nessa hipótese, não há como reconhecer, como já adiantado, uma hierarquia entre as leis de planejamento dos vários entes federados, mesmo que de esferas distintas, sendo o art. 18 da Constituição Federal claro ao dispor que "(a) organização político-administrativa da República Federativa do Brasil compreende a União, os Estados, o Distrito Federal e os Municípios, todos autônomos nos termos desta Constituição" (grifos nossos). 
Excetuadas as políticas públicas que, como já mencionado, dispõem de uma organização estabelecida por leis de caráter nacional, como Educação e Saúde, o que torna mais simples delimitar os aspectos da relação horizontal que se mostrar necessária entre os entes envolvidos, a dificuldade maior se constata em outras, nas quais esta facilidade não se faz presente.

A multiplicidade de possibilidades permite vislumbrar não haver uma solução abrangente, aplicável à generalidade dos casos, todas as vezes em que houver uma política pública operacionalizada em regime de cooperação federativa, com compartilhamento de recursos, materiais, humanos, financeiros ou de outra natureza.

As relações entre os entes federados apresentam diversas origens e naturezas, o que pode impactar diretamente nas relaçóes interfederativas que se estabelecem entre os entes federados inseridos no contexto de um programa, uma ação ou uma política pública realizada em regime de cooperação, o que exigirá uma avaliação casuística.

É o caso, por exemplo, da aplicação do recém-aprovado "Estatuto da Metrópole" (Lei n. 13.089, de 12 de janeiro 2015), que estabeleceu "diretrizes gerais para o planejamento, a gestão e a execução das funções públicas de interesse comum em regiôes metropolitanas e em aglomerações urbanas instituídas pelos Estados, normas gerais sobre o plano de desenvolvimento urbano integrado e outros instrumentos de governança interfederativa, e critérios para o apoio da União a ações que envolvam governança interfederativa no campo do desenvolvimento urbano" (art. 10). O regime de "governança federativa" criado prevê o "compartilhamento de responsabilidades e ações entre entes da Federação em termos de organização, planejamento e execução de funções públicas de interesse comum" (art. 2ª IV), e será regulado em lei complementar (art. 5º, III). Há de se destacar, para o interesse específico da questão ora abordada, que a governança federativa terá entre seus princípios a prevalência do interesse comum sobre o local, o compartilhamento de responsabilidades, a autonomia dos entes da Federação e a efetividade do uso dos recursos públicos (art. 6 I, I, II e VI), e observará a diretriz específica de "implantação de processo permanente e compartilhado de planejamento" (art. 7o, I), com a "compatibilização dos planos plurianuais, leis de diretrizes orçamentárias e orçamentos anuais dos entes envolvidos na governança federativa” (art. 7o, VI). E lista entre os instrumentos para viabilização os planos setoriais interfederativos, os fundos públicos, os consórcios públicos, os convênios de cooperação, os contratos de gestão e as parcerias público-privadas interfederativas (art. 9º, II, III, VI, VI, VII e $\mathrm{X}$ ), sendo possível formular planos setoriais interfederativos para políticas públicas (art. 10, $\$ 1^{\circ}$ ). Disciplina ainda a participação da União, que "apoiará as iniciativas 
dos Estados e dos Municípios voltadas à governança interfederativa, observados as diretrizes e os objetivos do plano plurianual, as metas e as prioridades fixadas pelas leis de diretrizes orçamentárias e o limite das disponibilidades propiciadas pelas leis orçamentárias anuais".

Isso ilustra bem a ampla gama de possibilidades que pode reger as relações interfederativas no âmbito do planejamento orçamentário, uma vez que se está diante de uma lei nacional - aplicável a todos os entes da federação - que remete à lei complementar específica (aplicável aos entes federados envolvidos, e formalmente com superioridade hierárquica sobre as leis próprias de cada ente) a ser elaborada para cada hipótese, nas quais serão estabelecidas as regras a serem obedecidas pelo sistema de planejamento orçamentário das administrações públicas participantes. Nesse caso, a interpretação dar-se-á no contexto de um sistema juridicamente organizado, que acaba estabelecendo as regras que regerão a relação horizontal entre as normas de planejamento orçamentário, e permitirá adotar soluções compatíveis com os princípios e diretrizes nele previstos.

A Constituição Federal prevê a edição de leis complementares que fixem normas para a cooperação entre os entes federados no art. 23 , parágrafo único, ${ }^{37}$ evidenciando a possibilidade de se estabelecerem regras que regulem essas relações, o que pode e deve incluir o aspecto financeiro e, consequentemente, o planejamento orçamentário, fundamental para o bom funcionamento das ações implantadas em regime de cooperação federativa. Mais uma possibilidade de ampliação dos regimes jurídicos específicos para reger essas relações.

Outras hipóteses podem ser observadas em casos que apresentam graus de semelhança com o ora descrito, que viabilizam um amplo leque de instrumentos de cooperação a ajustes federativos, com muitos exemplos dentro do próprio ordenamento jurídico brasileiro. O PPA federal 2004-2007 previu os "pactos de concertação", sobre o qual falaremos no item 5.1 - "Planejamento orçamentário, cooperação e coordenação federativa", para implementação de ações do referido plano. $\mathrm{O}$ Plano Nacional de Cultura prevê os "acordos de cooperação federativa”, objeto de referência no item 5.3 - "O poder de atração do orçamento central”, por meio do qual se viabiliza a integração ao Sistema Nacional de Cultura. Há também os convênios e contratos de repasse, entre muitos outros instrumentos. Existe previsão legal para que diversas modalidades de cooperação federativa insiram-se no sistema de planejamento orçamentário, como se pode constatar do disposto no art. $35 \mathrm{da}$ Lei n. 10.180/2001, ao prever que “(o)s órgãos e as entidades da Administração

37 Com a redação que foi dada pela Emenda Constitucional n. 53, de 2006. 
direta e indireta da União, ao celebrarem compromissos em que haja a previsão de transferências de recursos financeiros, de seus orçamentos, para Estados, Distrito Federal e Municípios, estabelecerão nos instrumentos pactuais a obrigação dos entes recebedores de fazerem incluir tais recursos nos seus respectivos orçamentos", e art. 38, $\$ 10$, da Portaria Interministerial n. 507/2011, segundo o qual “(é) condição para a celebração de convênios a existência de dotação orçamentária específica no orçamento do concedente, a qual deverá ser evidenciada no instrumento, indicando-se a respectiva nota de empenho", deixando clara a necessidade de compatibilização desses atos de cooperação federativa com um sistema de planejamento governamental. ${ }^{38}$

Vale ainda registrar o aspecto para o qual chama a atenção André Carvalho, quando, ao se referir ao tema, considera as diversas possibilidades de relações envolvendo coordenação, integração, hierarquia e subordinação entre PPA uma questão política, e anota ainda que a questão da hierarquia entre planejamentos não se mostra algo consensual entre as federações. ${ }^{39}$

Assim, a análise da relação jurídica horizontal que se estabelece entre as normas de planejamento orçamentário leva à conclusão de que são múltiplas as possibilidades interpretativas, a depender do regime jurídico a que estão submetidas, que podem apresentar grande variabilidade, exigindo uma avaliação casuística que deve observar as normas aplicáveis em cada caso, com vistas ao cumprimento dos objetivos fundamentais e observando os princípios constitucionais.

38 Nesse sentido: DALLAVERDE, Alexsandra Kátia. As transferências voluntárias no modelo constitucional brasileiro, p. 146-147.

39 CARVALHO, André Castro. Direito da infraestrutura: perspectiva pública, p. 412-415. 